\title{
2
}

\section{From paths to traditional territory: Wayfinding and the materialisation of an ancestral homeland}

\author{
Wen-ling Lin
}

\section{Introduction}

The concepts of an 'ancestral home', 'old tribe' and 'traditional territory' have often been the main concerns at various Taiwanese indigenous social and cultural events. Every 'return to the old site' or 'exploration for an old tribe' implies, more or less, the loss or disappearance of an original habitat. Following the instructions of their elders, younger generations search through the mountains for the sites where their ancestors used to live and work. Wayfinding while walking to a certain place has become a common theme of these activities. The trajectories of such movements circumscribe the possible scope of a traditional territory. By walking, indigenous peoples make repeated visits to their ancestral home, giving form to their 'ancestral homeland' as conceived by their elders. The concept of a 'homeland' comes into being during the process of searching and a relationship is formed between people and the land. This differs drastically in terms of feelings and expression from the dematerialisation of space in contemporary social life. 
Laipunuk is a region in the southeastern section of Taiwan's Central Mountain Range, including the upper and middle reaches of the Luye River, a tributary of the Beinan River. It encompasses the present-day townships of Yanping and Haiduan in Taitung County, the western parts of the Maolin and Taoyuan districts of Kaohsiung City and the border between Wutai Township and Pingtung County. According to the literature, in the early days, it was where the Ngerarukai Rukai ('Oponoho' or Wanshan in Chinese), the East Rukai Danan community, the Southern Tsou and the Puyuma lived. The original meaning of 'Laipunuk' in Bunun is 'area originally belonging to the Rukai people', referring to the land of the Wanshan people.

In 1941, the Japanese forced those Bunun who were still living in the Laipunuk area to move down from the mountains. Since then, Laipunuk has been uninhabited and has become a 'blank spot' on the map.

Sixty years later, at the end of 2001, the Bunun descendants of Laipunuk initiated an expedition to find a way home. These expeditions continued for 18 years. In the first three years of this period, expeditions were undertaken as a collective action by the descendants of the Laipunuk people living in Yanping and Haiduan townships in Taitung County. After 2004, it became an annual settlement-seeking journey of the Husungan family. In 2006, two members of the Husungan family, Tama Nabu and Nas Tama Biung, ${ }^{1}$ believed the action of 'going home' to Laipunuk could not stop. These two then joined Dahu to begin rebuilding the Husungan family's house. In 2008, with the idea of using the 'mountain as a school', the creation of a Laipunuk elementary school was promoted. ${ }^{2}$ A virtual elementary school centred on the mountains was opened, later renamed the Laipunuk Pasnanavan ('Laipunuk Place of Learning'). ${ }^{3}$ Liu Man-Yi, one of the founders of the Laipunuk Pasnanavan, proposed that 'the ancient paths and the residual wall is the classroom, and the tribe's Tama is the teacher'. This school in the mountains incorporated the theme of 'going home' into its curriculum.

1 Tama ('father') is the honorary name given to a male elder. Nas is a Bunun title for a deceased person.

2 Adhering to the educational philosophy of the 'mountain as a school', the entire tribal area of Laipunuk is a rich school with no walls, in which nature provides endless learning materials.

3 The tribal elders said pasnanavan in Bunun has the meaning not just of 'learning' but also of a 'place of learning'. 


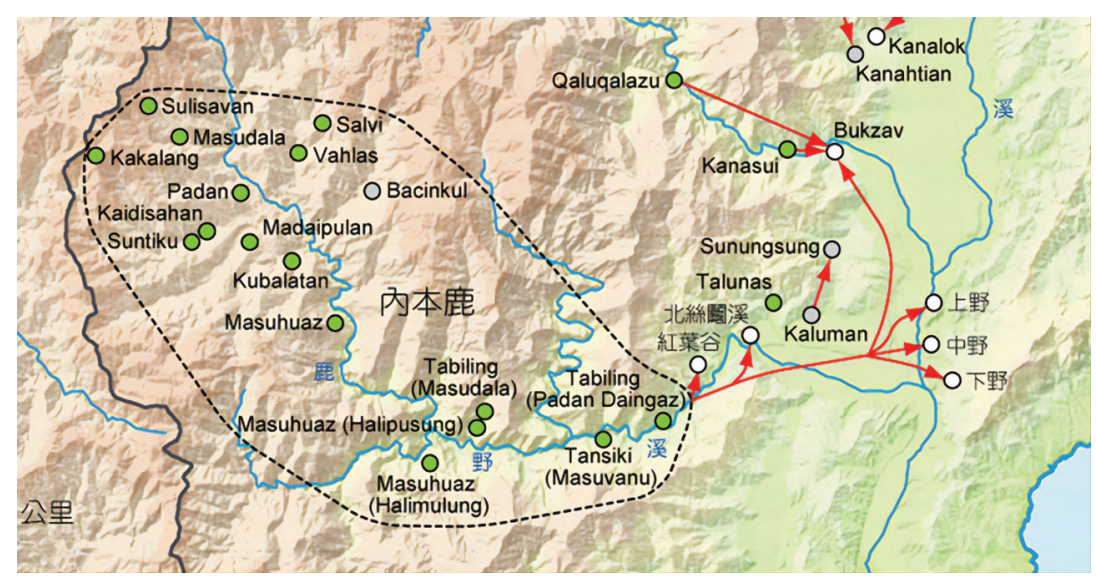

\section{Map 2.1 Map of Laipunuk}

Source: mapstalk.blogspot.com/.

This chapter will focus on the initial stage of the Laipunuk: kulumab ${ }^{4}$ ('Laipunuk: Going Home') from 2001 to 2004, and, based on two documentary films recorded during this period, it explores the origins of the Bunun descendants' efforts to find their way home and retrace their roots. This involves an examination of the ideas and meanings of paths and the way they lead to a home.

Tahai Binkinuaz (Chinese name: Tsai San-Shen), one of the Bunun descendants of Laipunuk, participated in the 'root-seeking' (kilim maiasang) activity of the first period. He filmed, directed and edited Open the Window of Taiwanese History: Return to Laipunuk (2002) and Back to the Land Where the Navel is Buried (2003). These two documentaries recorded the 10 'going home activities' between the winter of 2001 and April 2003.

The Bunun descendants' physical activities of 'root-seeking' generally involved a small group of tribal people walking into the depths of the mountains-activities through which they experienced and recognised the environment and natural sites where their ancestors had led their daily lives. Walking as a group defined the interaction between these people and their material space. Through this process, individuals gained access to traditional knowledge of the ecology, animals and plants that had provided an existence on the land. They followed a variety of paths

4 Kulumah means 'going home' in the Bunun language. 
that formed a network allowing them to comprehend their ancestors' traditional life. Here the path became the object and the medium for a flow of ideas, meanings and memories.

Dan is the Bunun term for a 'path' and mu-dan means 'to walk' or 'to go'. Mudadaan means 'walking', and Bunun people often use this term when discussing which way to go. What is special is the expression kilim daan ('find the way'). There is no expression for 'opening a path', but the closest is kan-anak kilim daan ('I am looking for a way'), and this was often used because there are no paths in many places and people need to find their own way (Valis Ishahavut, Personal communication, 2019).

According to Aliman (2006: 47), the traditional Bunun paths of Laipunuk were divided into hanupan dan ('hunting trails') and huma dan ('agricultural paths'), which had different uses. The main focus was on the routes from an asang ('settlement') ${ }^{5}$ that were used for hunting and when transporting harvested crops, to arrange marriages and alliances, sell products or fight with foreigners. It was only during the Japanese occupation that a cross-ridge trail was made through the Laipunuk; it was only 1.5 metres wide and was called the 'crossroad'. It followed the contours of the ridge and was convenient for transporting Japanese mountain cannons. The grass beside the trail was cut for 20 metres on either side to defend against the Bunun, who were good at ambush.

Wayfinding and walking as a theme became intertwined with issues of traditional territory, tribal mapping and traditional knowledge of the ecology linking people to the land. This chapter discusses the significance of these activities to investigate and respond to three theoretical questions: 1) How does the act of walking define a traditional cultural territory and its boundaries? 2) What discourse is expressed through such bodily actions that differs from a literal, geometric, panoramic and state-oriented discourse? 3) What kind of unnamed objects and unexpressed relationships does a path mediate?

5 Asang is the term for a settlement consisting of one or several families. 


\section{Research approach: Walking, mapping and mediations}

Christopher Tilley (1994), in his book A Phenomenology of Landscape: Places, paths, and monuments, adopts a phenomenological approach and suggests that archaeologists can use the sensory experience of phenomenology to explore and explain a cultural landscape and how people in a particular location interact with the environment and landscape in which they live. Tilley's research on sensory experience suggests that people who understand the world of experience are key to phenomenological methods (1994: 11). The understanding and description involved in phenomenology lie in the subject's experience of things-that is, the relationship between being and being-in-the-world. 'Being-in-the-world' means that, in the process of objectification, people 'separate themselves' from the objective world and make the world an object that can be understood and grasped. Such a process is based on a certain 'gap'. Only with such a 'gap' and distance can people initiate perception—seeing, listening, touching — for physical action, intentionality and matters such as belief, memory and evaluation. These perceptions allow an understanding of the world of phenomena (Tilley 1994: 12).

'Being-in-the-world' implies that the human subject is a mediator in the world and becomes physically oriented towards the world's original openness. The relationship between the individual and space is a lived space or, in Merleau-Ponty's view, a phenomenal space (2014). It is different from objective space. Objective space is a homogeneous space of geometry and science. In this objective space, all positions are outside other positions and each can be replaced with another. ${ }^{6}$ Phenomenal space is derived from activity, and life's relationship in this space produces the ability for bodily movement and the intentional relationships formed by such movement (Young 1980: 149).

This meaning of place is closely related to human activities, narratives or depictions. Michel de Certeau (1984: 115-36) believes that each space has a 'spatial story' that belongs to a locality. The uniqueness of a space can be understood through a spatial story. The emotional sharing of stories between individuals can establish collective awareness and identity. Participating individuals can also find their own positioning and orientation in history.

6 Objective space can be defined by pure externality. In this space, the body becomes an objective object that does not differ from other objects. 
Christopher Tilley's (1994) discussion of spatial stories begins with paths, movements, landscapes and narratives, in addition to highlighting humans as the subject of experience with their perceptions of the surrounding environment. The discussion, telling and description of this have an important influence on the formation of meaning.

Tim Ingold (2000) also observed the influence of 'narrative' on environmental perception. The discourse and images embedded in the environment enable people to reorganise the environment in their own memories. In Ingold's view, the story reveals the storyteller's perception of the environment and of himself. Therefore, through a story, the environment and the storyteller are organised in a developing, interrelated relationship. In addition to the discussion of the relationship between stories, narratives, subjective dynamics and local construction, Ingold clearly highlights the key role played by walking in understanding the environment and a lived-in world. He argues that research on walking will bring a change of perception (Ingold 2004: 315). On different occasions, Ingold (see 2004, 2010, 2011a, 2011b) has elaborated on the epistemological meaning of 'the human body as a moving active subject in space', arguing that researchers need to be sensitive to the skill of the footsteps (embodied skills of footwork) and the subsequent transformation of learning, empathy, perception and consciousness.

Walking as embodiment-as a social and imaginative practice-can be a way of telling, commenting on, performing and creating stories and places. This requires attention to imagination in generating understanding, connections and questions (Elliott and Culhane 2017: 95). A walk itself is not just following a path from one place to another; a walk is a performance that fosters active participation in the environment (O'Neill and Hubbard 2010: 56). Walking is an art, but also an act of consciousness, habit and practice. It is shaped by both local conditions and the landscape. 'Walking is the medium and outcome of a spatial practice, a mode of existence in the world. The analogy can be taken further in the consideration of paths' (Tilley 1994: 29).

A path as the outcome of spatial practice allows the passage of people, ideas and memories. According to Arjun Appadurai (2015), a path has two interrelated dimensions-mediation and materiality-which work together. ${ }^{7}$

7 Mediation is a concrete practice and materiality is the place of mediation. 
A path is also a medium for storage. A path leads people to construct a database, a process that makes the path itself a rich source of cultural knowledge. As a medium, a path promotes communication. It belongs to (at least) two parties who are engaged in communication and negotiation (Herzogenrath 2015: 1).

\section{Moving the body, drawing the living region of the ancestors}

Among the various tactics adopted by the Japanese against Taiwan's aborigines, the process of resettlement through collective migration had the most profound impact. In 1919, the Japanese colonial government trialled moving groups in various parts of Taiwan. The first trial move of the Bunun people began in 1922.

The Japanese Government spent two full years (1924-26) constructing a 64-kilometre Laipunuk garrison road, which ran through Kaohsiung and Taitung. ${ }^{8}$

A year after the Da Guan Shan Event in 1932,9 the Japanese began a large-scale relocation of the Bunun people in this area to better control them (Haisul Palalavi 2006: 197). In 1941, when the Japanese colonial government moved the last three Bunun households from Siusui, ${ }^{10}$ the Laipunuk group removal was completed (Aliman 2006: 92; Tahai Binkinuaz 2004: 108). The Bunun of Laipunuk were forced to migrate from deep in the mountains to the villages of Hongye, Taoyuan, Wuling, Yongkang and Lushan in Yanping Township. 'Laipunuk' as a location has since disappeared from the map.

8 The road rises from the western branch of the mountains, climbs over the Central Mountain Range and descends to the Luye River, before turning east to the northern silk village (now Taoyuan Village in Yanping Township). Along this section of the Laipunuk police road, there are various police stations at named sites: Dah Dah (Hong Ye), Siusui (Qing Shui), Kaili (Feng), Kakaiyu (Jiajiadai), Tavilin (Tao Lin), Takibana (Ju), Pisbadan (Shou), Takibadan (Chang Pan), Zhao Ri and Sakaivan (Chu Yun).

9 The Da Guan Shan Event occurred in the Shibuya station of the Taitung Hall in Taiwan, where Lamataxinxin Husangan Istanda and his Bunun followers launched a raid against the ruling authorities. Lamataxinxin and others attacked three police officers stationed in Shibuya, causing two deaths and one serious injury. At the end of that year, Lamataxinxin and others were arrested and executed by the Japanese police.

10 Siusui: Qing Shui in Chinese; Clear Water in English.

11 The residents of five villages in Yanping Township, Taitung County, are the Bunun who have been displaced from Laipunuk (see Haisul Palalavi 2006: 204, 207-09; Li Minhui 1997: 58-60; Huang Ying-Kuei 2001: 151, 181, 195, 208; Ye Jia-Ning 2002: 96). 
Around 2001, after 60 years away from their homeland, the Bunun descendants of Laipunuk began the effort to go home. Based on the oral histories of tribal elders and the cartographic skills of the townspeople of Yanping, the descendants of Laipunuk ventured into the mountains to explore their homeland. They recorded the distribution of the tribes of Laipunuk and the usage of familial landholdings, hunting fields and other traditional sites. Ecological knowledge, historical events and the interactions among these tribes were recorded.

\section{From kilim maiasang ('settlement-seeking') to kulumah ('going home') ${ }^{12}$}

In 1988, after the abolition of martial law, representatives of Taiwan's indigenous peoples took the opportunity to fight for their land rights and demonstrated on the streets to promote the 'returning my land movement'. Between 1997 and 2004, the Executive Yuan Aboriginal Committee (Aboriginal National Council of the Executive Yuan) began the first wave of surveys of indigenous peoples' traditional territories and tribal mapping. As part of this, the Bunun people of Yanping and Haiduan townships in Taitung County initiated the process of kilim maiasang ('settlement-seeking'). ${ }^{13}$ They launched 10 Laipunuk exploration efforts beginning in the winter of 2001 and continuing to April 2003.

These Laipunuk exploration activities tried to find ways of returning to their ancestors' homelands. This attempt to return to the Laipunuk had a forerunner. According to Nabu, a member of the Husungan family, Haisul was one of the first individuals to return to the area. Haisul was the initiator of the rebellion of Laipunuk against the Japanese on 9 March 1941. The story of the Laipunuk rebellion sparked the emotions of future generations and set the tone for the Laipunuk events 60 years later.

According to Nabu Husungan Istanda:

Katu sisivung sia tasa tu asang a sat u mulushulushu. Katu tahaz takisingsing tan tu dalah, asang, haimangsut, mais nihai naka, madaz iswuka. [Don't fall in love with the land, don't fall in love

12 Asang means 'a settlement'. The prefix mai refers to the 'past' or a 'former time'. Mai-asang thus refers to a former home or old tribal settlement.

13 These activities were mainly organised and promoted by the Bunun Cultural and Education Foundation. 
with the flat land, settlements, and appliances. Keep moving and migrating. If you are stranded in a place for too long, you will die and disappear] ${ }^{14}$

After 60 years, the descendants of Laipunuk who lived on the plains below the mountains began to respond to the exhortations of their elders. Their exploration efforts were similar to those in earlier times. Instead of migrating to new places to open up wild land, sow seeds and settle down, as in the old days, the Bunun descendants of Laipunuk sought their roots and attempted to re-establish the sites that had long disappeared from the map.

Because the move down from the mountains had occurred long ago, the 'way' to return to Laipunuk required repeated surveys. From different starting points and paths, the Bunun descendants of Laipunuk struggled to find the homeland of their elders' memories on the blank space on the map-a nameless place-and gradually allowed its location and boundaries to emerge with each footstep they took.

Tahai Binkinuaz, one of the Bunun descendants of Laipunuk, filmed, edited and directed Open the Window of Taiwanese History: Return to Laipunuk, which records 10 of the exploration efforts in detail. The film is in Bunun language with Chinese subtitles. The gist of the film-the motif of the excursions, the core concept and the central activities-is clearly stated:

In order to retrieve the history and culture of Laipunuk and to seek the traces left behind by our ancestors, at the end of [the] year 2001, the descendants of Laipunuk started returning to their native place. We asked the elders for help and interviewed them. We also searched for historical documents and materials. In the end, we used our feet to explore and feel our native home. (Tahai Binkinuaz 2002)

This statement clearly expresses the necessity of seeking 'the traces left behind by the ancestors' to retrieve 'the history and culture of Laipunuk'. Their determination to find the roots of their history and culture thus stimulated the Bunun to launch their efforts to return home. 'Finding a way home' is achieved through continuing cycles of intention and realisation.

14 Nabu extended the words of the elders; the Bunun were a migratory people and the elders believe the survival of their culture depends on their constant movement (Nabu Husungan Istanda, Interview, 2016). Also see Liu Man-Yi (2017). 
On 10 December 2002, Human Rights Day, the Bunun elders were taken back to the previous location of Laipunuk by helicopter. This project was sponsored by the Council of Cultural Affairs of the Executive Yuan and was named 'Na Kulumahin Kata' ('We Are Going Home'). This return to Laipunuk — the elders' first helicopter flight-was made possible only by the efforts of their descendants who explored the location and built a temporary landing pad for the helicopter. Before setting off, the elders told their ancestors:

Ancestors! We are going to visit you tomorrow. Do not be scared, because we will take a helicopter, a machine that you have never seen before. We are not there to shoot you. We are there to visit you. So please do not be frightened when you see us. Please bless us. Your descendants will go back to pay you a visit from now on. So, ancestors, please take care of your offspring! This time, we are going home to do the things we have to do.

For the Laipunuk-born elders who had been unable to return to their homeland for more than half a century, the trip was more than just a homecoming, allowing them to walk on their homeland and 'meet' their deceased family. The elders also wanted to see the place where they had 'buried their navels' - the place from which they had come. In the film, we see a closeup of the elders' faces, showing the emotions of homecoming. For this scene, the narrator says: ${ }^{15}$

In the past, when we were born, we Bunun people would bury our navels in our homes. But our elders haven't seen the remains of their umbilical cord for a long time. They haven't returned to their homeland for a long time. ${ }^{16}$

The first six minutes of Open the Window of Taiwanese History: Return to Laipunuk presents the elders' return to their homeland by helicopter and the core idea behind this return. Later scenes focus on the many other explorations in the mountains. Near the end of the film, the 'We Are Going Home' project and the Bunun elders' return to Laipunuk by helicopter are presented again. At this point, three major phases of the film can be recognised:

15 This passage was reported widely in the media at the time.

16 The Bunun traditionally bury the umbilical cord of a newborn under the house. The umbilical cord is the link between the new life and the mother; the house is regarded as the birthplace of the mother's culture. Therefore, burying the umbilical cord under the house symbolises the connection between the newborn and the family. 
1. The elders board the helicopter, see their long-lost homeland from above and then disembark to physically stand on their land, welcomed by the younger generation.

2. The younger generation explores the mountains, trying different routes to search for their former tribal locations.

3. The elders, once disembarked from the helicopter, together walk on their homeland.

With its continuous inscription of 'walking into the forests to look for their original land', the film portrays the Bunun's persistence in searching and the physical labour involved. Through the arrangement of these images, the elders express their previously repressed emotions. In the third section of the film, while walking on the path with others, one elder says:

This is my path. This is my path and so I am crying. I cannot stop myself from crying. When I was here, I was about 13 or 14 years old ... 65 years have passed, and now I am 80 years old. I have come back again to walk on this land. ${ }^{17}$

Another elder finds the site where he buried his navel. He squats on the ground, plants a tree and says:

Orange tree! You have to grow up well here alone in the mountain. You were brought here by me, from the low country to the place I was born. Keep watch on my navel for me. It is fortunate that you are here. You have to grow well.

The middle section of the film records the descendants of Laipunuk walking into and among the forests and mountains. They use their feet to search for their former tribal land. In every effort of exploration, events and memories change as a result of the judgement of and choices made by the descendants. During the first return trip, a narrator says:

In the winter of 2001, we explored Laipunuk for the first time. Because it was the first time, only five people participated in the activity. We walked along the previous Japanese paths since they were easier for us. We started from Siusui police station and arrived at the Mamahav tribal site. We saw the drawbridge that was severed by Haisul in the Laipunuk event. When the Japanese paths were no longer available, we walked down into the river valley and

17 Nabu Husunggan Istanda mentioned several times on different occasions that when his mother saw her long-lost hometown, she was overcome by emotion. 
waded across the stream to get to Kaili ${ }^{18}$ station. At Kaili station, there were the remains of Japanese temples. We honoured the children who were mistakenly killed by Haisul during the conflict between the Japanese and the Bunun people. We found close by there was a thriving community of Taitung cycads. We only spent four days and three nights and we came home.

For the Bunun who participated in this excursion, walking on the Japanese paths was a particularly touching experience. They saw the sites where historic events had taken place and thus remembered the tragic incidents narrated by the elders. Through the narrator's commentary and the scenes presented, we witness how the people waded across streams and climbed precipices. We also experience the mist deep in the mountains and the plants that grow there. The narratives and images give concrete expression to the native place and its living conditions as described by the elder man in the film. The film thus becomes like a texture than can be 'touched' by the younger generation.

With the hope of representing the original tribes, the descendants describe the places they finally 'saw' after their painstaking walks:

Mamahav: A tribe that has many chillies.

Masuvanu: A tribe that has lots of honey.

Halimudun: A tribe that is full of weeds.

Halipusung: A tribe that has limestone.

Masudala: A tribe that has many maple trees.

Tavilin: A tribe of peach trees.

Bacingul: A tribe that grows many ring-cupped oaks.

Takivablas: The tribe of the Takivahlas family, a tribe by the river.

Takisayan: The tribe of the Takisayan family, a tribe beside a great rock.

Kailisahan: A tribe that has smooth slate covers. ${ }^{19}$

Madaipulan: A tribe where the river is muddy.

These visual details and the recognition of placenames create an identity with the land, infusing the places with emotion and memory (see Basso 1996). ${ }^{20}$

18 Kaili: Feng in Chinese; Maple in English.

19 This tribe is named after a large, smooth slate-covered house.

20 In the Bunun tradition, each tribe or family had a different name depending on its hunting trail or tribal path. Therefore, different families and tribes have their own names for paths. 


\section{A tribal map made through wayfinding (by walking)}

In 2002, those born in Laipunuk returned to their old tribal lands by helicopter. This was named 'Laipunuk first year'. The first exploration team that was sent out set up a white house in front of the Takivahlas house to open the land and to plant millet. In the sixth year of Laipunuk, the Takishusungan (Husungan family) returned to reconstruct their house. They have since returned every year between December and January, continuing into the eighteenth year of Laipunuk.

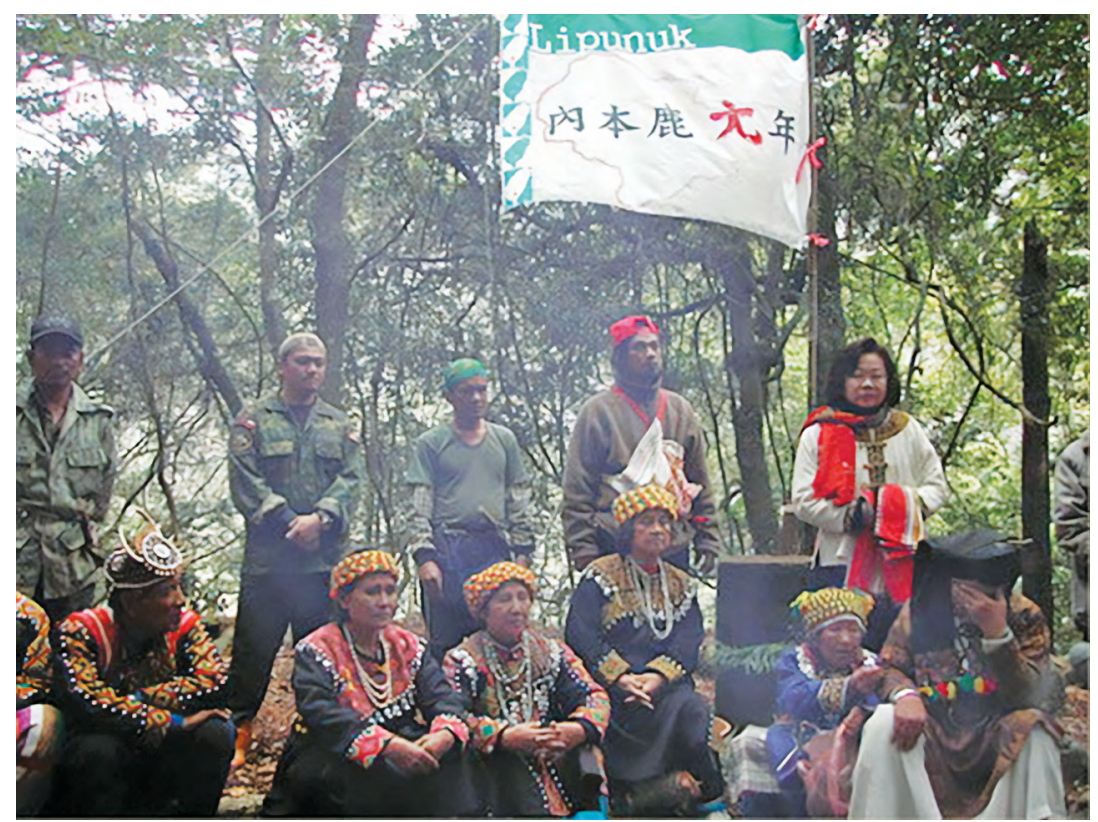

Plate 2.1 Bunun raise the banner of the first year of Laipunuk in 2002 in an old settlement

Photo: Bunun tu Asang (Bunun Cultural and Educational Foundation).

The younger generation of Laipunuk did not base their search for the mountain locations of former tribes on any readily available map; nor did they use advanced navigation techniques. Instead, these descendants carried out a process of 'wayfinding' to return to their native land. They invariably encountered significant 'objects' that were not indicated on any map but were nevertheless meaningful to them. These 'objects' could be a 'sign' of the environment, a change in the weather or various traces left 
by humans. The 'archives' to which this younger generation referred were their own experiences and the stories they had heard from the elders. In this context, the meaning of 'wayfinding' for these descendants was not simply bodily movement through space. Rather, their physical labour was a process of experiencing and understanding how they related to their excursion and the environment, and the significance it produced.

As a result of the many possibilities of each excursion, the routes taken differed. Twenty-four people participated in the second trip to Laipunuk. This trip was full of unexpected events and uncertainty. During the section of the film that covers this second trip, the voiceover in Bunun slowly and calmly describes the journey:

We entered the mountain from Sakusaku ${ }^{21}$ of Kaohsiung County and headed for the tribes near the Pisbadan ${ }^{22}$ police station. But we got lost in the mountains. When we waded across the stream, we encountered a great canyon. For two days, we did not discover the source of its water. It was really difficult. On the sixth night, we communicated with our ancestors' spirits. On the seventh morning, our leader, Aliman, told us: 'An old tribe was located here. It is right above where we camped.' In this way, we found the place where the elder Chen Sheng-yuan buried his navel, mazaibulan. ${ }^{23}$

Each time an expedition was held, the Bunun tried to explore the mountains using a different route. Sometimes they took the forest paths of Yanping; other times they left Sakaivan ${ }^{24}$ station from Kaohsiung; and still other times they waded across the Luye River looking for possible paths. Step by step, these Bunun followed their ancestors' paths, travelling further and further. Sometimes their route overlapped with a previous one and sometimes they found new routes. Without the guidance of a map, they moved by 'wayfinding' (in contrast to the way people who use maps move in a linear manner from one point to another). The conditions of the ancestors' living spaces became clearer and clearer. The 'wayfinding' activity of the return to Laipunuk thus became a mapping of the former tribes (see Ingold 2000). The particularities of this map were produced through walking. The tools for making this map were the people and their movement, their interactions and their experiences in the region,

21 Sakusaku: Liu Kuei in Chinese; Six Turtles in English.

22 Pisbadan: Shou in Chinese; Long Life in English.

23 See Liu Man-Yi (2017).

24 Sakaivan: Chu Yun. 
and the map was marked out by spoken memories of specific names, stories and events. The map had a uniqueness, with its own temporal depth and significance.

When these placenames were drawn, one by one, Laipunuk became a storytelling tribal map. This map specifically reproduced the distribution of households, fields and environmental features-the family profiles of the local tribes at the time, as well as their hunting grounds, traditional lands and associated historical events-restoring the life and history of the Laipunuk people, connecting them with the land and prompting memories and homesickness among the elders.

The search through the mountains for Laipunuk was intended not to verify its existence as a place on a map, but to entitle Laipunuk, which had been concealed, and to open it to further reproduction of meaning: 'We explore with our feet', drawing the route of 'uncovering'. ${ }^{25}$ The traces left by the people's footprints defined the scope within which historical conjunctures were to be found. These conjunctures outlined a region of the 'old tribe'-a significant place to their Bunun descendants. ${ }^{26}$ Laipunuk, which had become a 'blank' on the map, offered these Bunun descendants a specific space in which to form social relationships within which each individual could create an identity as a Bunun Laipunuk. In this way, they developed a discourse of spatial politics through which they could claim their rights politically (Massey 2005: 195).

Because 'wayfinding' was a recurrent process, mapping could not be concluded after just one excursion and needed to be an ongoing process. This activity had several layers of meaning. The actor-perceiver in this process of 'wayfinding, had to become immersed in the texture of the environment, and based on these experiences and observations, had constantly to adjust perceptions and judgments to a path that would lead toward a destination' (Ingold 2000: 20). Such immersion in the environment and constant searching coloured the 'mapping' of the return to Laipunuk with what Robert Rundstrom (1991: 6) has called a 'process

25 Starting from the sixth minute of the film, the voiceover states: 'Till now, we have been to our homeland to site-investigate 10 times. We took the route from Linben to enter the mountain, as well as the route from Mount Chuyun in Kaohsiung. Sometimes we go upstream along the river. The old route no longer exists now. We have to find our own route back home.'

26 John Gray (2003: 228), in his ethnographic research in the Scottish Borders, proposes that a boundary is drawn in accordance with the activities of the subjects, and describes a circle as a way to differ the 'we' from others. 
cartography' whereby the 'charting of the map (wayfinding/mapping) is situated both within the culture (communication between generations and ancestors) and in the longer context of trans-cultural conversation', endowing it with the possibility of communication within the tribe and with non-tribal people. Furthermore, since 'wayfinding' was an ongoing process, the charting of a map was never a once-and-for-all act. The map could be redrawn as different people participated in the journey and brought divergent levels of mobility. The flexibility of and communication during mapping led to the next mapping process and the appearance of yet another map (Rundstrom 1993: 21). This pattern of work enabled the charting of the tribal map to gain more and more details and to reconnect the histories between the tribes' (Bunun Blog). ${ }^{27}$

The different routes of the excursions uncovered divergent scenes and traces of memory. As a result, the terrain of the ancestors' lives became intertwined with the bodies of those searching and their experience and understanding of the environment and the words of the elders. This understanding was embodied in the exercise of walking: observing, touching, listening, feeling and climbing. The things learned from this experience could be considered embodied knowledge that was produced through the functioning and cooperation of multiple sensory organs.

The key phrase, 'Return to Laipunuk', became the core concern of the Bunun's claim for their right to revive their traditional territory. The action taken by the descendants of Bunun Laipunuk to realise such a goal was walking - an action that is highlighted in their documentaries. An interaction between the Bunun and their land was rebuilt each time they walked along ancient routes (see Massey 2005: 130). When the Bunun returned to their abandoned tribal lands, their history of 'displacement' under successive governments unfolded. From a historical viewpoint, a resistant force was released at the sites of historical events (see Keith and Pile 1993: 3).

27 www.bunun.org.tw/tw/index.asp?au_id=56\&sub_id=160. 


\section{The path reconnecting the Bunun people and Bunun Laipunuk}

Returning to the former tribal sites brought the elders, the youth, children and all men and women together. To learn more about and become closer to their past, the younger generations would constantly ask the elders for help and clarification. The younger generations contacted the elders during fieldwork to learn more about their homeland at Laipunuk. ${ }^{28}$ This fieldwork created an active process of communication that conveyed different generations' ideas about their tribal history, experiences and knowledge. The process of 'going home' involved the experiences of generations and the exchange of inherited knowledge and also an active sharing of emotions and connections between different generations.

This communication between generations was not limited to the living. Every time the tribespeople undertook a trip home, they held rituals to tell their ancestors of their approach and to plead for their blessings for a safe return from the depth of the forests. Their journey implied a reconnection through time and space, a return to a symbiosis of the heavens and the earth. As a result, 'Returning to Laipunuk' was not merely a journey of 'settlement-seeking' (kilim mai-asang), but also an attempt to reconstruct the historical relationship of the Bunun with Bunun Laipunuk.

'Returning to Laipunuk' was also a social event that brought about interaction and reconnection among the Bunun while calling for an awareness of Bunun cultural identity and ethnic self-determination. According to the Bunun Blog, 'Returning to Laipunuk' was seen as an action that:

not only unifies the ethnic identity and awareness of the Bunun of Yanping county, but also restores the Bunun subjectivity and the correctness of an historical interpretation from a Bunun viewpoint. Furthermore, as a base of taking charge of Laipunuk, this action aims to rehabilitate the traditional territory of Bunun, which will be the foundation of resource management and land attribution. ${ }^{29}$

28 Preparations for 'Returning to Laipunuk' included interviews with older Bunun, a literature review, site investigation and other data compilation.

29 www.bunun.org.tw/tw/index.asp?au_id=56\&sub_id=160. 


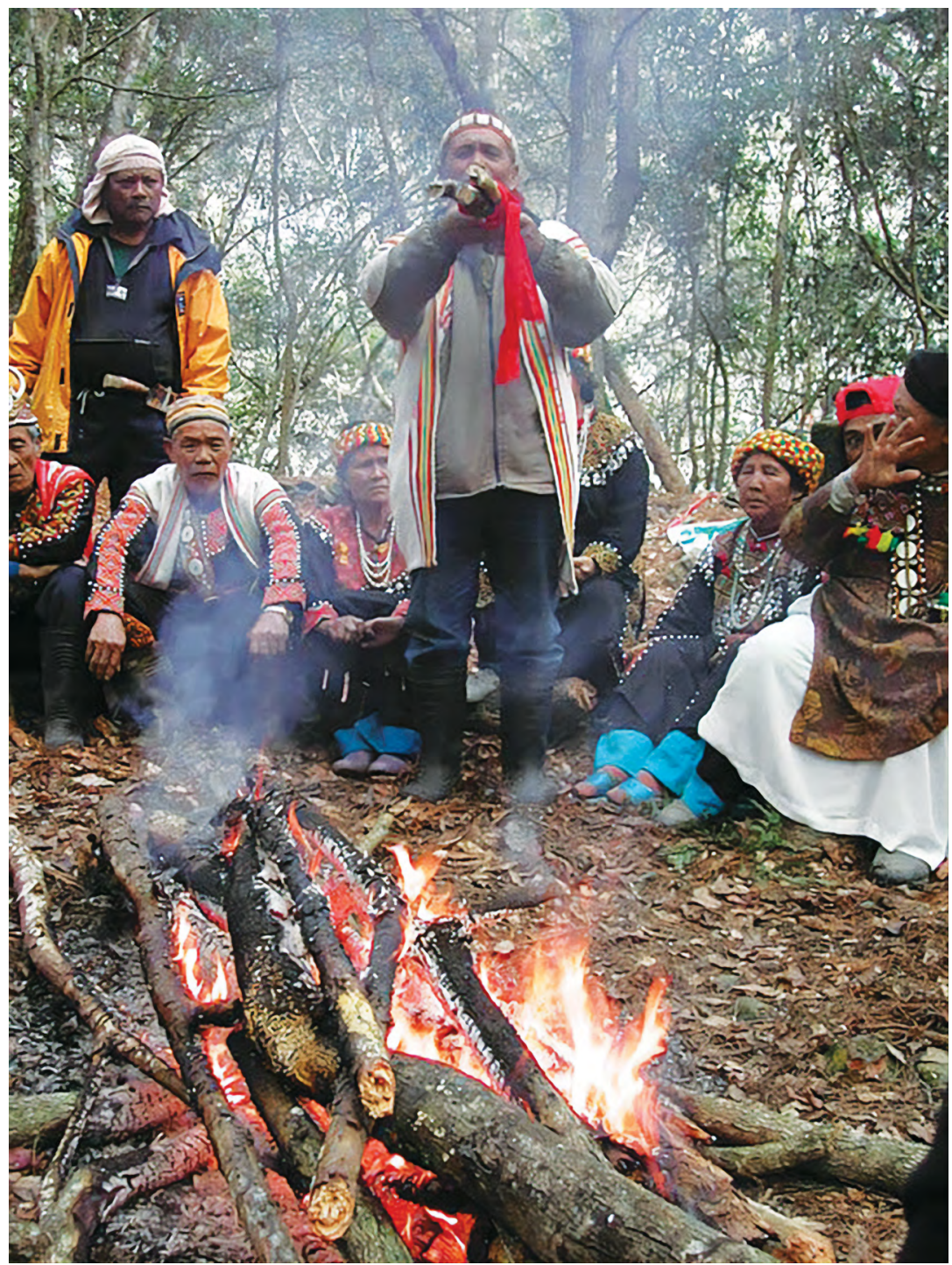

Plate 2.2 Sacrifice to the ancestors

Photo: Bunun tu Asang (Bunun Cultural and Educational Foundation).

In other words, 'Returning to Laipunuk' is the Bunun descendants 'walking on the way home'. These paths carry various flows of and communication between people, things, ideas, meanings and memories. Therefore, the path is a medium that carries and reveals various relationships and mediates between them. 
According to this statement, the activities of finding the way home over a complex area, clarifying a possible path and maintaining it by continuing to walk on it give the path meaning. Through its substance, the path allows people to continue to walk back and forth; goals appear, are realised and maintained. This gradual formation of paths allowed the former tribal locations to be identified, helped reveal the ancestors' way of living and then led to the reconstruction of houses. It opened the way for a journey of learning from the forest. It was an attempt at re-linking, and a lesson for the Bunun. The path clarified ideas. It offered not so much a spatial continuity of points as the connectivity of the group through time. As such, the path offers 'mediation'. It mediates various 'force fields' through negotiation, arbitration, connection and assembly. This path is a basis for relearning and becomes a cultural creation of the contemporary Bunun people. ${ }^{30}$

As people walked into the mountains and outlined the scope of the old tribes, the process of historicising was documented on film. The 'Returning to Laipunuk' and the trails followed on the way home were recorded in at least two mediums: the bodies of those walking and the images recorded on video. These two different mediums preserve a historical document of 'walking back to the homeland', serving an intermediary role through time and space to extend the significance of bodily action in different contexts.

'Through images, we hope to bring back the memories of the elders and remind the Bunun offspring of their affection toward Laipunuk. Therefore, a Laipunuk identity will be formed.' This paragraph was written in May 2002 in the proposal for the filming of Back to the Land Where the Navel is Buried. ${ }^{31}$ The director was one member of the site investigation team. His documentary Open the Window of Taiwanese History: Return to Laipunuk combines images and narration to create a specific narrative style. The film is framed around the site-investigation process, during which people walked into the mountains many times; yet the camera mostly focuses on the natural environment-the climate and plantsrather than on the people moving about. The director has tried to let the Bunun elders and the audience view the natural environment of the

30 The Bunun people left the forest and broke their connection with the land, making it difficult to be Bunun. The contemporary people who have a sense of identity with Bunun culture more or less experience the process of min Bunun ('recircling Bunun'). See also: laipunuk.blogspot.com/p/bununmin-bunun-tama-nabu-min-bunun-min.html.

31 www.bunun.org.tw/tw/index.asp?au_id=568sub_id=160. 
homeland directly through the camera, as if they were there with the site investigation team and could see and feel the place where their ancestors once lived.

The director presents his site investigation through images that show the audience both the physical and the psychic labour he expended during the journey. Although, compared with people's firsthand experience, the video itself was not necessary for the search process, as a recording tool, it does not function until the site investigation team arrives at a specific destination. The director sees and feels on behalf of those who could not be at the spot personally and transfers his experience through visual images, while presenting what he knows through stories told by the elders. The eyes of the director are internalised in the video, while his visual perception of the surroundings is embedded in the memories and knowledge passed down from the ancestors of Bunun. In other words, the flow of Bunun memories and affections toward the place are contained and transferred within this vision.

As MacDougall (1998) has pointed out: 'Image, as a way of representation, is something to be seen and touched.' Laura Marks, a film scholar, notes the connections between 'vision' and 'touch' through image representation: '[I]f seeing is considered a way of embodiment, then touch, as well as other sensory perceptions, play[s] a necessary role in such seeing' (Marks 2000: 22). Through the director and the sensory images he presents, the Bunun people saw and remembered the old tribe. The key to rekindling memories lies in multiple sensory perceptions. Images in a film can make direct contact, reviving people's memory and demanding their sensory participation. As the audience identifies the subject of these actions, they participate in the meaning and experience signified in the narration.

According to the Bunun Blog: 'When the recorded images of siteinvestigation were played to the elders, they were moved to tears. ${ }^{32}$ The idea of a homeland came into being as their offspring climbed through the mountains. On their way to the site, their offspring experienced the change in climate and saw living things in their natural landscape. The journey to the homeland demanded that people walk back and forth, and images of this walking could be played and replayed afterwards. Watching this walking provided access to the experience of physical labour involved in the production of possible meanings (Lee and Ingold 2006: 68). 


\section{Conclusion}

'Wukan mas maidudu tu dan, kaupa mas maza na kandapanan su [There is no easy way but to look where you choose to walk].' Nabu said this in a thoughtful way as he was going home: 'The road is still very long; [I encourage] everyone to go slowly!' This 'slow walking' allowed people of different generations to take different paths but meet each other on the way home. The path home was the way people emerged as Bunun ('the real humans', in Bunun language). For those who walked on this path, it was not just a way of moving, but a way to bring forth a cultural inheritance. The path was born of walking, and this walking shaped the landscape. Over time, the landscape became a repository of common knowledge and symbolic meaning. This path home became a means of linking tradition and generating new knowledge. By this means, people drew forth different relations and put forward issues of the existence, survival and maintenance of culture. Through this path, a contemporary chain of identity was negotiated and transformed, and given cultural rejuvenation.

\section{References}

Aliman (Wang, Tu-Shui). 2006. Exploring the history of the Bunun ISDAZA (Laipunuk) from a local perspective. [In Chinese]. Masters thesis, Institute of Ethnic Relations and Culture, National Donghua University, Hualien, Taiwan.

Appadurai, Arjun. 2015. 'Mediants, materiality, normativity.' Public Culture 27(2): 221-37. doi.org/10.1215/08992363-2841832.

Basso, Keith. 1996. Wisdom Sits in Places: Landscape and language among the western Apache. Albuquerque, NM: University of New Mexico Press.

de Certeau, Michel. 1984. The Practice of Everyday Life. Trans. by Steven Rendall. Berkeley, CA: University of California Press.

Elliott, Denielle and Dara Culhane. 2017. A Different Kind of Ethnography: Imaginative practices and creative methodologies. Toronto: University of Toronto Press.

Gray, John. 2003. 'Open spaces and dwelling places: Being at home on hill farms in the Scottish Borders.' In Setha M. Low and Denise Lawrence-Zuniga, eds, The Anthropology of Space and Place: Locating culture, pp. 224-44. Oxford: Blackwell. 
Haisul Palalavi. 2006. The Origin of Bunun Tribes and History of Tribal Migration. [In Chinese]. Taipei: The Executive Yuan Aboriginal Committee.

Herzogenrath, Bernd, ed. 2015. Media Matter: The materiality of media, matter as medium. New York: Bloomsbury. doi.org/10.5040/9781501304835.

Huang, Ying-Kuei. 2001. Taitung County History: Bunun Zu. [In Chinese]. Taitung County: Taitung County Government.

Ingold, Tim. 2000. The Perception of the Environment: Essays on livelihood, dwelling and skill. New York: Routledge.

Ingold, Tim. 2004. 'Culture on the ground: The world perceived through the feet.' Journal of Material Culture 9(3): 315-40. doi.org/10.1177/ 1359183504046896.

Ingold, Tim. 2010. 'Footprints through the weather-world: Walking, breathing, knowing.' Journal of the Royal Anthropological Institute 16: 121-39. doi.org/ 10.1111/j.1467-9655.2010.01613.x.

Ingold, Tim. 2011a. Being Alive: Essays on movement, knowledge and description. London: Routledge. doi.org/10.4324/9780203818336.

Ingold, Tim. 2011b. Redrawing Anthropology: Materials, movements, lines. Farnham, UK: Ashgate.

Keith, Michael and Steve Pile, eds. 1993. Place and the Politics of Identity. London: Routledge.

Lee, Jo and Tim Ingold. 2006. 'Fieldwork on foot: Perceiving, routing, socializing.' In Simon M. Coleman and Peter Collins, eds, Locating the Field: Space, place and context in anthropology, pp. 67-86. Oxford: Berg.

Li Minhui. 1997. The group migration policy and social reconstruction of Taiwanese mountain tribes during Japanese rule: Bunun River Basin family as an example. [In Chinese]. Masters thesis, Department of Geography, National Normal University, Taipei.

Liu, Man-Yi. 2017. Kulumah Laipunuk: Finding the roots and going home. [In Chinese]. New Taipei City: Walkers Cultural Enterprises.

MacDougall, David. 1998. Transcultural Cinema. Princeton, NJ: Princeton University Press.

Marks, Laura. 2000. The Skin of the Film: Intercultural cinema, embodiment, and the senses. Durham, NC: Duke University Press. doi.org/10.1215/ 9780822381372. 
Massey, Doreen B. 2005. For Space. London: Sage.

Merleau-Ponty, Maurice. 2014. Phenomenology of Perception. Donald A. Landes, trans. New York: Routledge.

O’Neill, Maggie and Phil Hubbard. 2010. 'Walking, sensing, belonging: Ethnomimesis as performative praxis.' Visual Studies 25(1): 46-58. doi.org/10.1080/ 14725861003606878.

Rundstrom, Robert. 1991. 'Mapping, postmodernism, indigenous people and the changing direction of North American cartography.' Cartographica 28(2): 1-12. doi.org/10.3138/5J46-51T2-7M42-316G.

Rundstrom, Robert. 1993. 'The role of ethics, mapping, and the meaning of place in relations between Indians and whites in the United States.' Cartographica 30(1): 21-28. doi.org/10.3138/2362-P365-2G88-1P65.

Tahai Binkinuaz (Tsai San-Shen), dir. 2002. Open the Window of Taiwanese History: Return to Laipunuk. [In Chinese]. Documentary, 60 mins.

Tahai Binkinuaz (Tsai San-Shen), dir. 2003. Back to the Land Where the Navel is Buried. [In Chinese]. Documentary, 10 mins.

Tahai Binkinuaz (Tsai San-Shen). 2004. Laipunuk Bunun tribal migration before 1942. [In Chinese]. Masters thesis, National Chengchi University, Taipei.

Tilley, Christopher. 1994. A Phenomenology of Landscape: Places, paths, and monuments. Oxford: Berg.

Ye, Jia-Ning. 2002. The History of Taiwan's Indigenous Peoples: A history of Bunun. [In Chinese]. Nantou, Taiwan: Taiwan Historica.

Young, Iris Marion. 1980. 'Throwing like a girl: A phenomenology of feminine body comportment motility and spatiality.' Human Studies 3: 137-56. doi.org/ 10.1007/BF02331805. 
This text is taken from Austronesian Paths and Journeys, edited by James J. Fox, published 2021 by ANU Press, The Australian National University, Canberra, Australia.

doi.org/10.22459/APJ.2021.02 